\title{
Assessing retro-reflective markers (RRMs) usage on heavy vehicles with respect to MS 828:2011
}

\author{
Mohd Amirudin M.R ${ }^{1, *}$, Ahmad Noor Syukri Z.A ${ }^{1}$, and Kak D-Wing ${ }^{1}$ \\ ${ }^{1}$ Malaysian Institute of Road Safety Research (MIROS), 43000 Kajang, Selangor, Malaysia
}

\begin{abstract}
Malaysia is continuously developing and enhancing the safety system and policies for road users. One of the essential elements of safety is a good marking and thus the visibility of vehicles on the road. Since 2011, MS 828:2011 has been gazetted to guide industry on the right specification to follow with regards to RRMs. However, the RRMs that being used by heavy and long vehicle including in the current market were not up to the standard. Thus, the objectives of this study is to identify the current status of RRMs in Malaysia besides to measure the photometric values of current RRMs and to determine the usage rate of substandard RRMs on heavy vehicles and current market. Market surveillance and sample testing were conducted to determine on current RRMs usage and to analyse the RRMs with respect to MS 828:2011. As a result, $62 \%$ of RRMs condition on heavy vehicles are still not in a good condition or covered by dust. Also, only $4 \%$ of the RRMs sample complied to MS $828: 2011$. From this paper, it can be concluded that majority or $96 \%$ of the RRMs in current market and have been used by current heavy vehicles are substandard markings.
\end{abstract}

\section{Introduction}

Every year more than 6000 people are killed in road accidents in Malaysia. Approximately 1000 of these fatalities are car occupants and motorcyclists, killed in collision involving rigid and articulated type's trucks and rear-end crashes are one of the frequently occurring types of crashes [1]. Malaysia is continuously developing and enhancing the safety system and policies for road users to reduce the number of crashes and fatalities on the road. One of the essential elements of safety is a good marking and thus the visibility of vehicles on the road. In order to better visibility of long, heavy goods vehicles and their trailers, etc., these vehicles have to be marked with effective RRMs. This marking has to be from highly reflective materials which can guarantee better visibility during night and poor weather conditions.

Since 2011, MS 828:2011 Malaysian Standard has been gazetted to guide industry on the right specification to follow with regards to RRMs. However, industry readiness was compromised at the time of implementation in terms of product compliance and test

* Corresponding author: mohdamirudin@miros.gov.my 
facility. Fast forward to 2014, the test facility was finally ready and the industry was eager to obtain certification for their products.

The implementation of MS 828:2011 was scheduled on 1st July 2014 for all new trucks and trailers. A 6-month grace period was given for all fleet operators to implement such installation and for awareness purposes. However, the implementation for old heavy and long vehicles that was scheduled by early 2015 will be implemented by 1 st July 2016 stage by stage.

Currently, the RRMs that being used by heavy and long vehicle including in the current market were not up to the standard with respect to colorimetric, photometric, dimension and etc. Before full implementation, this paper will assess the compliant RRMs usage on heavy goods vehicles towards MS 828:2011 in Malaysia. Objectives of this study are to identify the current status of RRMs in Malaysia with respect to MS 828:2011 besides to measure the photometric values of current RRMs. The usage rate of substandard RRMs on heavy goods vehicles and current market also will be determined.

\subsection{Rear-end crashes and conspicuity issues in Malaysia}

Based on data from fatal crashes in Malaysia involving heavy commercial goods vehicles (HCGV), the most common types of crash configurations for HCGVs are head-on collisions (33\%) and rear impact collisions (28\%) as shown in Figure 1 [2]. Furthermore, for rear-end collisions involving HCGVs, the amount of light was not significant as the proportion of crashes that occurred during daylight and in the different categories of dark were $51 \%$ and $49 \%$, respectively [2].

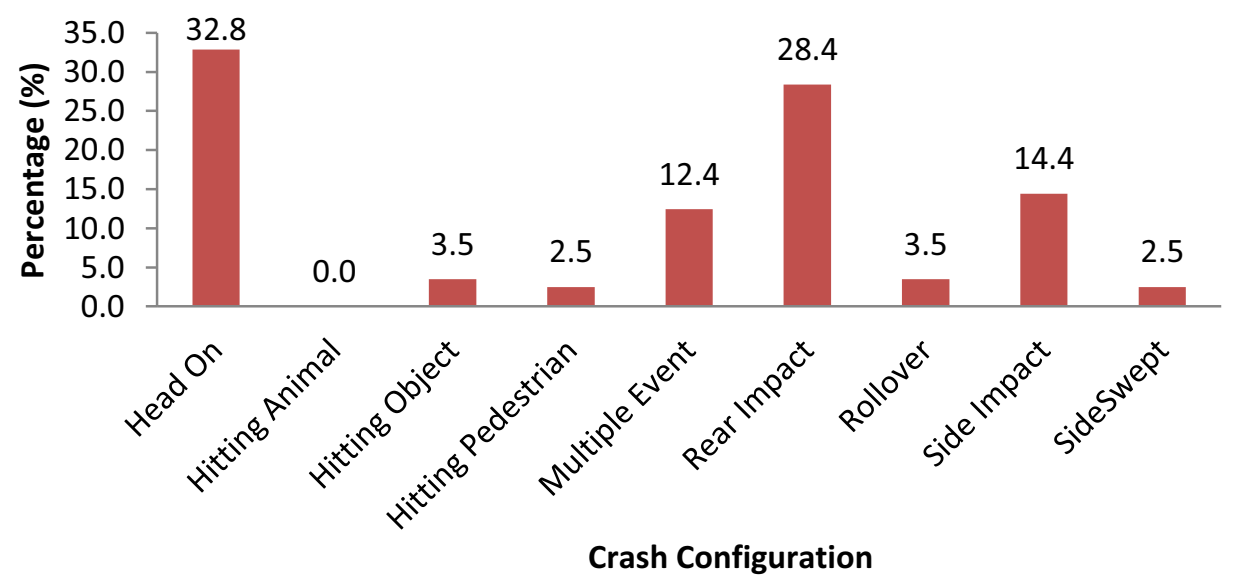

Fig. 1. Investigated HCGV fatal cases by crash configuration [2].

\subsection{Conspicuity markings}

In rear-end crashes, conspicuity plays a significant role, especially at night. To improve heavy goods vehicle visibility, heavy vehicles and their trailers need to be equipped with conspicuity markings, such as RRMs, and maintained in a good condition. The purpose of these markings are to increase the visibility of heavy goods vehicles to other motorists, especially in low light or and bad weather conditions. These markings brightly reflect the light emanating from the headlights of other motorists to warn them that they are closing in 
on a heavy vehicle. The alternating red and white on the rear of a HGV flags it as a heavy trailer and at the same time helps other road users gauge their distance and rate of approach [3].

In the United Kingdom (UK), the Road Vehicles Lighting Regulations (RVLR) (1989) require certain motor vehicles with a gross vehicle weight exceeding 7.5 tonnes to be fitted with retro-reflective rear marker plates in compliance to UNECE Regulation 70.00 (R70). The latest version of this regulation is R70.01, however in the UK R70.00 is still permitted.

Some vehicle operators also fit conspicuity markings to their vehicles. These are vertical and horizontal lines of retro-reflective material which emphasise the length and shape of the vehicle and also warn other drivers of their presence. UNECE Regulation 104 (R104) provides a technical specification for these conspicuity markings and their use on vehicles in the UK is optional. UNECE Regulation 48 (R48) is a European regulation that sets out harmonised installation requirements for vehicle lights and reflectors. Recently R48 was amended to mandate R104 specification conspicuity markings on certain new heavy goods vehicles and trailers [4].

\subsection{RRMs in Malaysia}

In Malaysia, all heavy goods vehicles, especially lorries and trailers, are required to use RRMs to provide other drivers with information and warnings. Two types of rear and side marking are specified by Malaysian Standard (MS) 828:2011 as shown in Figure 2 [5]. The dimensions of the plate, retro-reflective and coloured areas, and the proportions of the letters shall comply with the regulations currently in force in Malaysia.

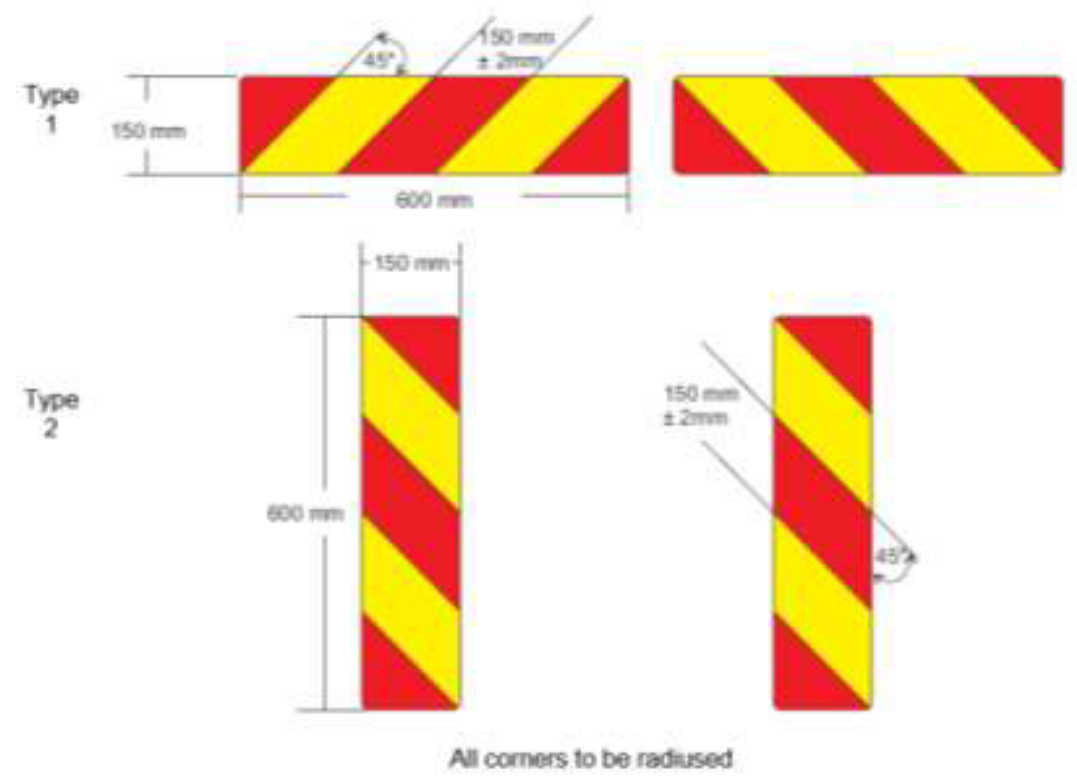

Fig. 2. Types of rear and side marking specified in Malaysia [5].

R104 provides a technical specification for high quality markings, which can be used to identify the contours of large vehicles. Meanwhile, MS 828:2011 specifies the requirements for marking with retro-reflective materials to be fitted to the rears and sides of heavy and long vehicles and trailers. MS 828:2011 was developed with reference to R70 and R104. 
The specified requirements include design, colorimetric, photometric, physical and mechanical properties of retro-reflective markers

Also, Table 1 below shows the minimum values of the coefficient of retro-reflection R' or photometric value for, yellow, white and red [5]. When the marking was achieved the minimum of photometric value as in Table 1, that marking was useful and were intended to make the vehicle more conspicuous to other drivers, so that they are aware of the presence of a large, potentially slow moving vehicle especially on the road.

Table 1. Minimum photometric values for yellow and red colour [5].

\begin{tabular}{|c|ccccc|}
\hline Observation angle, $\alpha^{\circ}$ & \multicolumn{5}{|c|}{ Entrance angle, $\beta^{\circ}$} \\
\hline$\alpha=0.33^{\circ}\left(20^{\prime}\right)$ & $\beta_{1}$ & 0 & 0 & 0 & 0 \\
& $\beta_{2}$ & 5 & 30 & 40 & 60 \\
\hline Colour & & & & & \\
Yellow & & 300 & 130 & 75 & 10 \\
White & & 450 & 200 & 90 & 16 \\
\hline
\end{tabular}

\begin{tabular}{|c|ccccc|}
\hline Observation angle, $\alpha^{\circ}$ & \multicolumn{5}{|c|}{ Entrance angle, $\beta^{\circ}$} \\
\hline$\alpha=0.33^{\circ}\left(20^{\prime}\right)$ & $\beta_{1}$ & 0 & 0 & 0 & 0 \\
& $\beta_{2}$ & 5 & 20 & 30 & 40 \\
\hline $\begin{array}{c}\text { Colour } \\
\text { Red }\end{array}$ & & 120 & 60 & 30 & 10 \\
\hline
\end{tabular}

\subsection{Effectiveness of RRMs}

The usage of retro-reflective tapes on trucks was effective and significantly reduced side and rear impacts [3]. The effectiveness of retro-reflective tape was assessed in four categories of dark conditions, namely "dark-not-lighted," "dark-lighted," "dusk" and "dawn," and it was found to reduce overall side and rear impacts into heavy trailers by $29 \%$. In "dark-not-lighted" conditions the use of retro-reflective tape reduced side and rear impacts by $41 \%$ [3].

In a study of night-time and day time accidents between a test group comprising 1000 vehicles equipped with contour markings and a control group of 1000 vehicles without such measures. After 2 years of testing the markings, 95\% of night-time collisions could have been avoided if trucks in the control group had retro-reflective visibility markings. Increased truck visibility due to reflective outline markings saw a $41 \%$ reduction of rearend crashes and a $37 \%$ decrease in side impacts [6]. Also the risk of an accident between truck and car was 30 times greater if the truck was without conspicuity markings [6]. 


\section{Methodology}

\subsection{Market surveillance}

Fifty sample of RRMs were purchased randomly at hardware and accessories shops. All the shops are located in Klang Valley Area. The purchased price of all the samples were recorded inclusive of Government Service Tax (GST). From these 50 sample, two samples were approved by SIRIM on the compliant towards MS 828:2011 and to be used as the references sample. Then, the dimension of these sample were measured.

\subsection{Sample testing}

Testing was carried out to profile the photometric values of RRMs sample for both yellow and red colour respectively by using photometer equipment as shown in Figure 3 . All the sample from market surveillance were tested. The photometer was able to measure retroreflectivity value in lux unit.

In addition, the sample from real world (lorries) were also collected and compared with the sample from current market. Those sample were collected randomly from 100 lorries which were stopped at Sungai Buloh Rest Area. The old RRMs on the lorries were exchanged with the new RRMs that complied to MS 828:2011. The old RRMs were cleaned and used as the sample for testing to get the photometric values reading. The height of those samples from the ground clearance for each lorries was also measured besides the dimension of the sample itself.

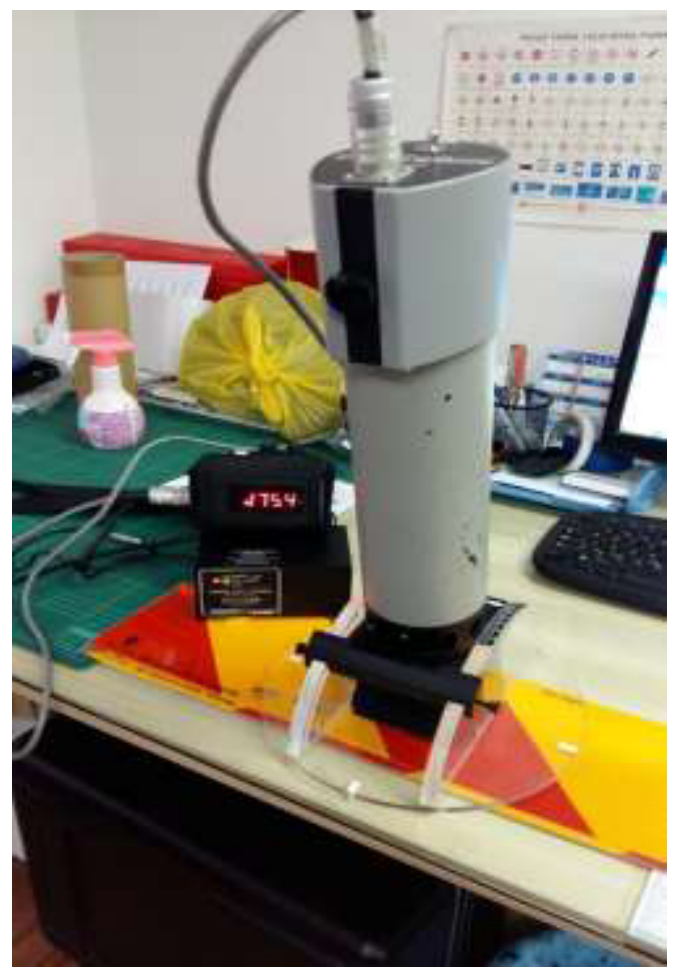

Fig. 3. Photometer equipment for testing. 
The testing was conducted twice for two different types of sample; current market and real world. Before conducting the test, the photometer was calibrated to get the accuracy of the reading. After that, the angle of the photometer was adjusted to $5^{\circ}$ as required by the MS 828:2011 [5] in order to get the actual reading of photometric values of all samples. The testing for each samples including both colour was repeated for three times in order to get the average reading.

\section{Results and discussion}

\subsection{Market surveillance and sample testing}

\subsubsection{Sample price}

From the market surveillance, the average price of the sample is about RM26.30. The lowest price is RM8.50 and the highest price is RM 85.00. The different between the highest and lowest price is about RM77.50. However, the two highest prices; RM65.00 and RM85.00 are the reference RRMs that complied to MS 828:2011.

\subsubsection{MS 828:2011 compliant (dimension)}

Dimension of the sample is another requirement for the compliance to MS 828:2011. Figure 4 shown the percentage of RRMs dimension that comply to the standard. Only $20 \%$ of installed RRMs complied to the standard. This shows that the awareness level on MS $828: 2011$ especially among lorry owners and fleet operators is low and need to be improved.

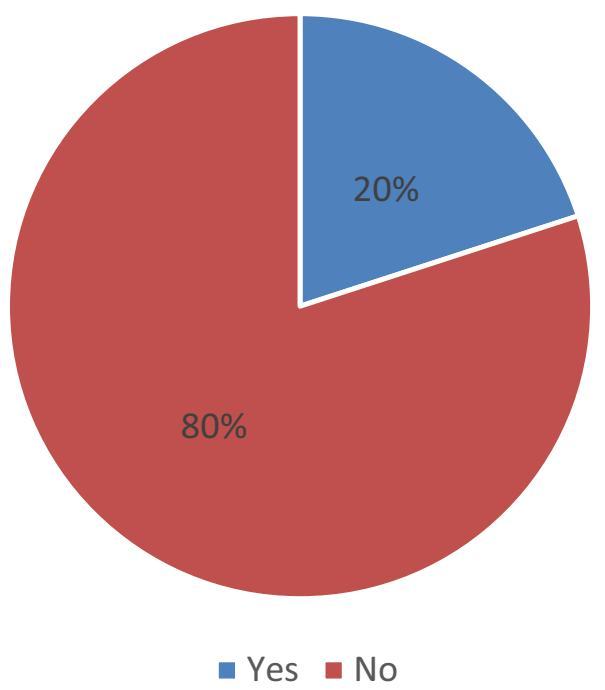

Fig. 4. MS 828:2011 compliant (dimension).

\subsubsection{MS 828:2011 compliant (photometric value)}

Photometric value is one of the specifications that has been considered on the compliant towards MS 828:2011. Table 1 above shown the minimum photometric values to be 
achieved for both yellow and red colour are 330 and 120 respectively. However, Figure 5 and 6 below show that only 4\% of the RRMs sample that have been analysed complied to MS 828:2011 which means that the other sample are counterfeit markings. The usage of counterfeit markings may not fully functional to reflect the light emanating from the headlights of other motorists to warn them that they are closing in on a heavy vehicle. This is dangerous to the other road users who are travelling at night time and they are at risk to be involved on the rear end crashes especially with the lorries and trucks that are using noncompliance markers.

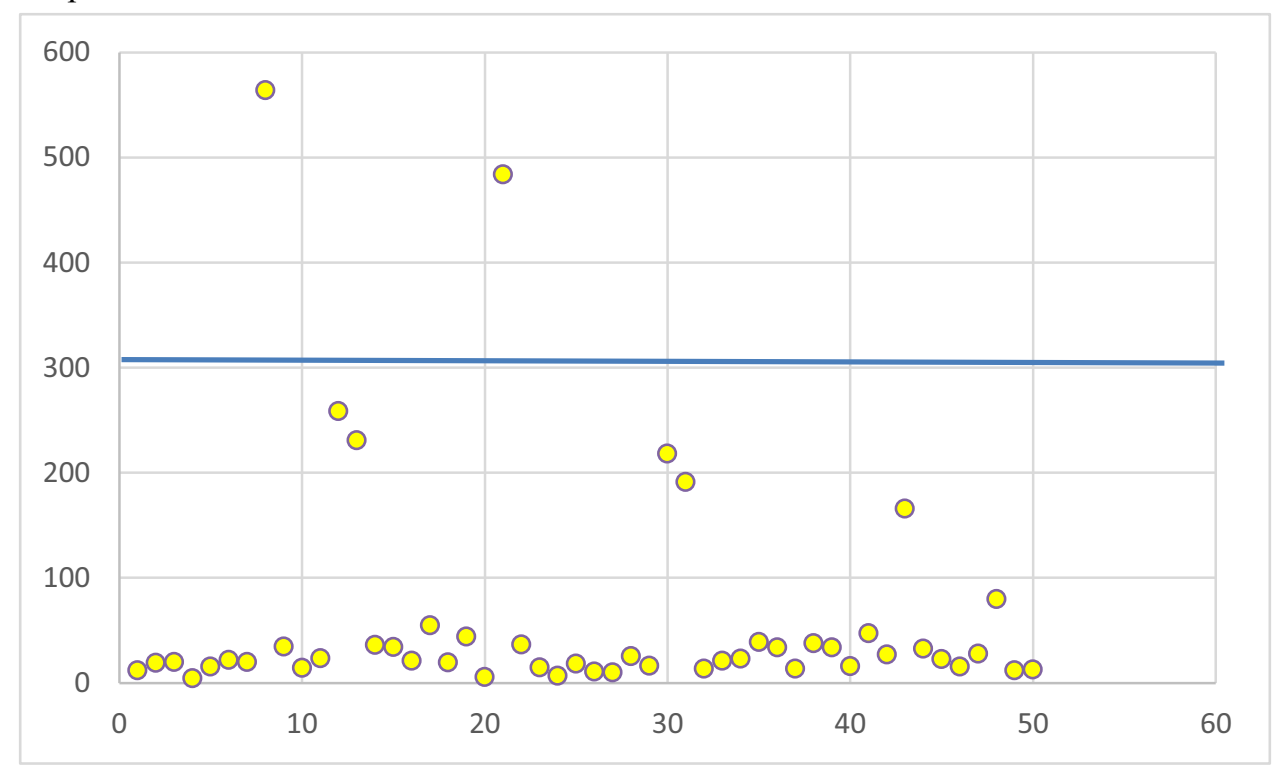

Fig. 5. MS 828:2011 compliant (Photometric value of yellow colour).

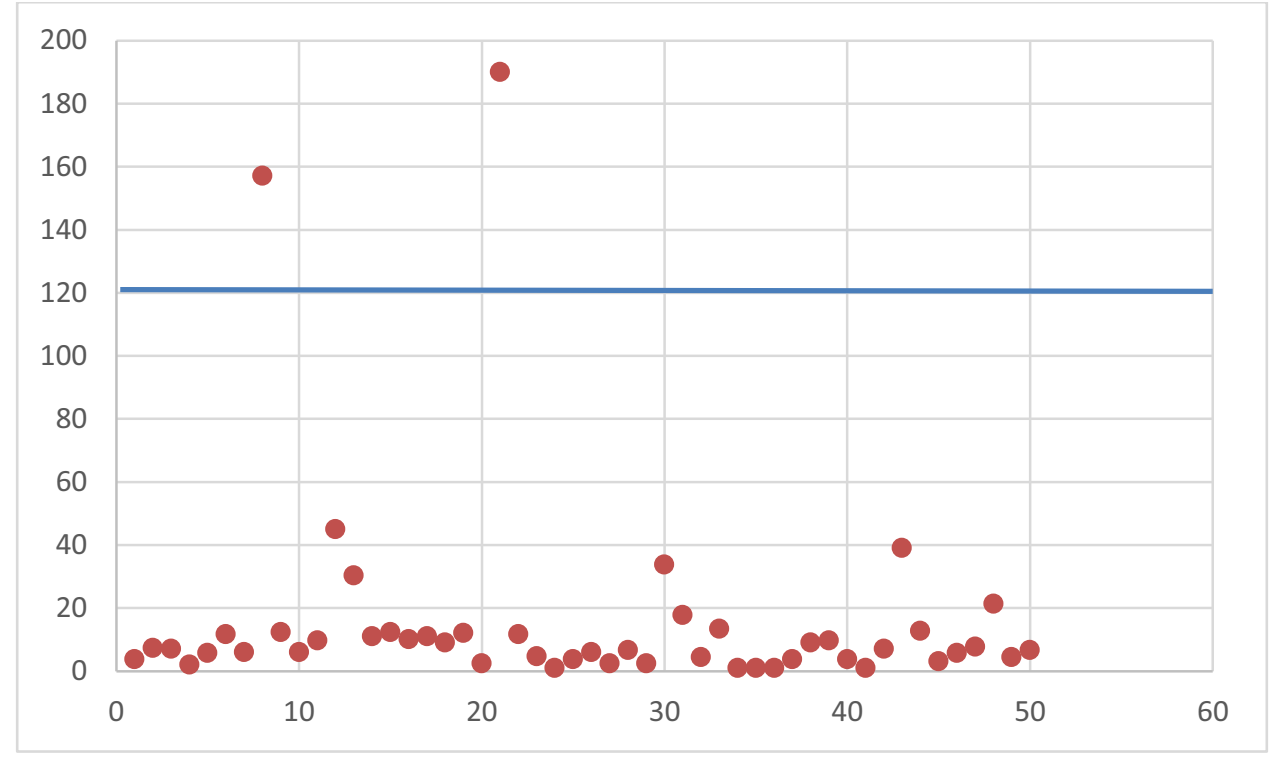

Fig. 6. MS 828:2011 compliant (Photometric value of red). 


\subsection{Real world sample testing}

At Sungai Buloh Rest Area, 100 sample are collected from both lorries and trucks. Table 2 shows the type of lorries involved for sample collection and the condition of old RRMs sample which collected from the trucks and lorries.

Table 2. RRMs condition on trucks and lorries.

\begin{tabular}{|c|c|c|c|c|}
\hline Sample, $\mathbf{N}$ & Lorry Type & & RMs Condit & \\
\hline \multirow{4}{*}{100} & Rigid & Good & $\begin{array}{c}\text { Covered by } \\
\text { Dirt }\end{array}$ & $\begin{array}{l}\text { Missing } \\
\text { Segment }\end{array}$ \\
\hline & $\begin{array}{c}50 \\
(50.0 \%)\end{array}$ & $\begin{array}{c}10 \\
(20.0 \%)\end{array}$ & $\begin{array}{c}33 \\
(66.0 \%)\end{array}$ & $\begin{array}{c}7 \\
(14.0 \%)\end{array}$ \\
\hline & Articulated & & & \\
\hline & $\begin{array}{c}50 \\
(50.0 \%)\end{array}$ & $\begin{array}{c}8 \\
(16.0 \%)\end{array}$ & $\begin{array}{c}29 \\
(58.0 \%)\end{array}$ & $\begin{array}{c}13 \\
(26.0 \%)\end{array}$ \\
\hline
\end{tabular}

\subsubsection{MS 828:2011 compliant (dimension)}

Figure 7 shows the number of RRMs installation compliant to the dimension from MS $828: 2011$. Only $19 \%$ of installed RRMs are found to be compliant and this percentage is almost same with the percentage from current market sample which is only $20 \%$.

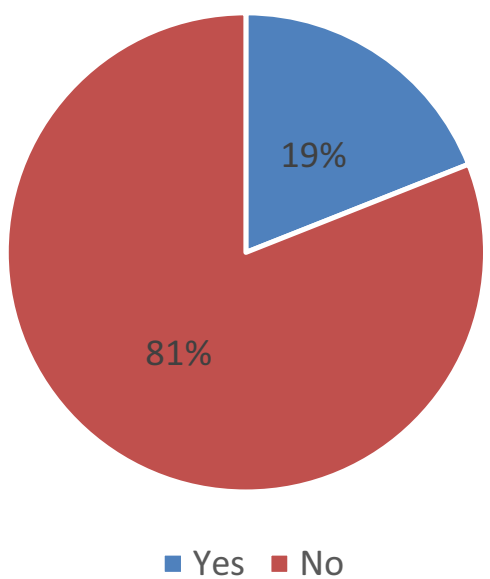

Fig. 7. MS 828:2011 compliant (dimension).

\subsubsection{MS 828:2011 compliant (photometric values)}

Besides the height of ground clearance and marker dimension, the photometric values are the other for the compliance towards MS 828:2011. However, both Figure 8 and 9 show that only $2 \%$ of yellow colour of the RRMs sample that have been analysed complies to 
MS 828:2011 while none of red colours complies to the standard. None of the samples from real world complies to the MS 828:2011 or on the other word, all the sample are counterfeit markings. The usage of counterfeit markings may not fully functional to reflect the light emanating from the headlights of other motorists to warn them that they are closing in on a heavy vehicle. This is dangerous to the other road users who are travelling at night time and they are at risk to be involved on the rear end crashes especially with the lorries and trucks that are using non-compliance markers.

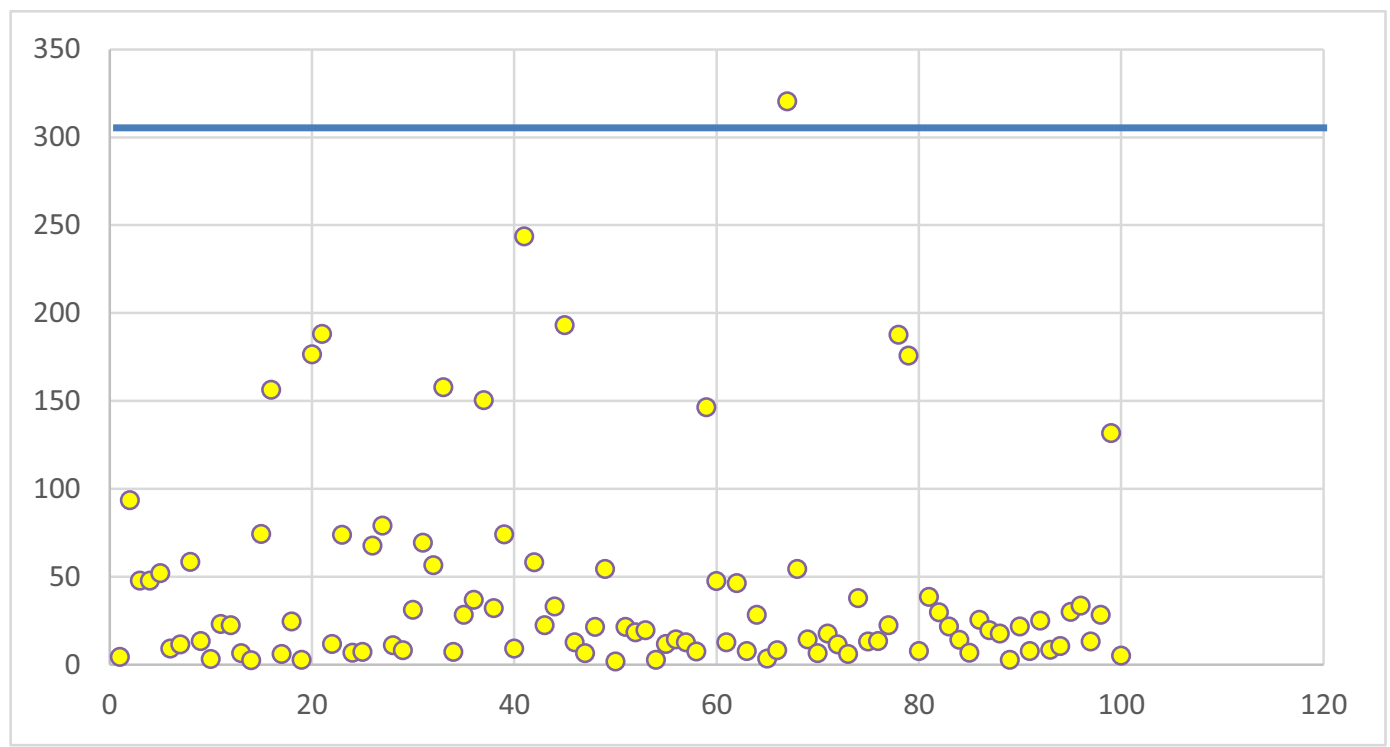

Fig. 8. MS 828:2011 compliant (Photometric values for yellow colour).

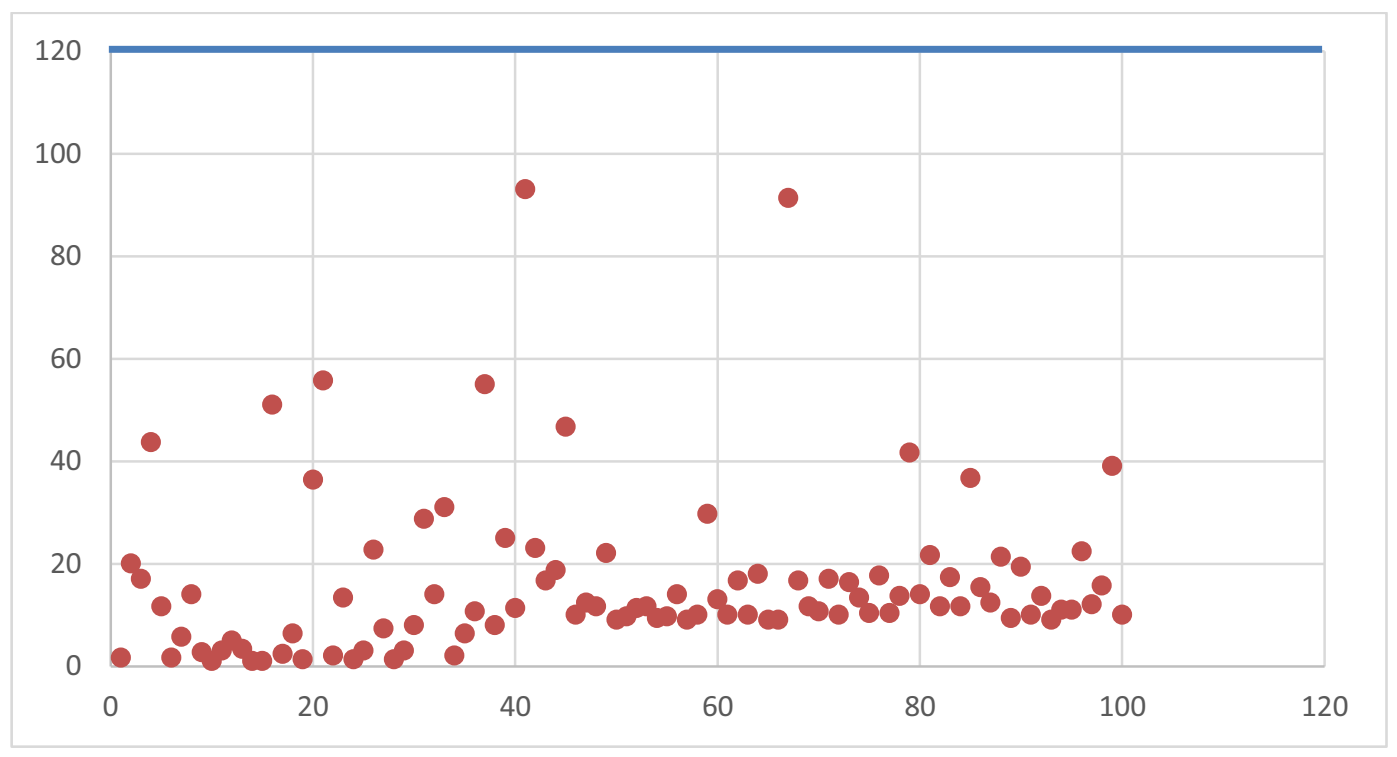

Fig. 9. MS 828:2011 compliant (Photometric values for red colour). 


\section{Conclusions}

In this paper, several conclusions are outlined as follows:

- From the market surveillance, the average price of the sample is about RM26.30 while the lowest price is RM8.50 and the highest price is RM 85.00.

- $62 \%$ of the RRMs on both types of lorries are found to be covered by dirt. When the RRMs are not in good condition such as covered by dirt, the marking will not be effective thus will not fully function to reflect the markers.

- $\quad$ For the sample from current market, only 4\% of the sample complies to MS 828:2011 while for the sample from lorries (real world), none of the sample complied to MS 828:2011.

- After the analysis is carried out, it is found that the usage rate for substandard RRMs on current market and real world are $96 \%$ and $100 \%$ respectively. It shows that the usage rate of substandard markers especially on the current market and real world in Malaysia is very high and need to be enforced by related agencies.

\section{References}

1. M. M. Huzaifah, Rear End Crash Compatibility Between Cars and Trucks in Malaysia: A Preliminary Study, presented at the The 8th Int. Forum of Automotive Traffic Safety (INFATS), Wuhu, China (2010)

2. A. N. Syukri, Heavy Commercial Goods Vehicle Crashes in Malaysia, Malaysian Institute of Road Safety Research (MIROS), Malaysia (2013)

3. C. Morgan, The Effectiveness of Retro Reflective Tape on Heavy Trucks, National Highways Traffic Safety Authority, Washington DC Report No. DOT HS 809222 (2001)

4. D. Babic, Impact of Heavy Vehicle Visibility on Traffic Safety, presented at the The International Scientific Conference - ZIRP 2014, Zagreb, Crotia (2014)

5. Department of Standards Malaysia and SIRIM Berhad, Malaysian Standard (MS828:2011), Road Vehicles - Rear and Side Marking - Specification (Second Revision), ed. Malaysia (2011)

6. P. D.-I. Schmidt-Clausen, Contour Marking of Vehicles, H.J. Laboratory of Lighting Technology, Darmstadt University of Technology Final Report FO 76 / 00, 8 (2000)

7. Amirudin M.R, Rear-end Markers (REMs) Issues involving Trucks and Lorries in Malaysia, Malaysian Institute of Road Safety Research (MIROS) (to be published)

8. A Berces, Improving Road Safety by Increased Truck Visibility, 3M Traffic Safety Systems Division, ARRB Conference, 25th, 2012, Perth, Western Australia, Australia (2012)

9. M.R.J. Baldock, A.D. Long, V.L. Lindsay, A.J. McLean, Rear End Crashes, Report No. CASR018, Adelaide, Australia: Centre for Automotive Safety Research, the University of Adelaide (2005)

10. Clare Lawton, John Richardson, Ruth Welsh, Assessment of The Safety Benefit of Retro Reflective Markings On HGVs and Buses, Report for Department for Transport USA, May (2005) 